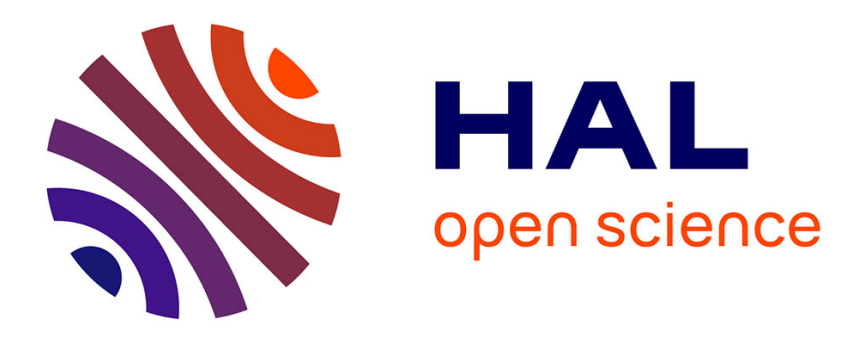

\title{
DISLOCATION MECHANISMS OF PLASTIC DEFORMATION OF ICE
}

\author{
A. Fukuda, T. Hondoh, A. Higashi
}

\section{To cite this version:}

A. Fukuda, T. Hondoh, A. Higashi. DISLOCATION MECHANISMS OF PLASTIC DEFORMATION OF ICE. Journal de Physique Colloques, 1987, 48 (C1), pp.C1-163-C1-173. 10.1051/jphyscol:1987124. jpa-00226269

\section{HAL Id: jpa-00226269 https://hal.science/jpa-00226269}

Submitted on 1 Jan 1987

HAL is a multi-disciplinary open access archive for the deposit and dissemination of scientific research documents, whether they are published or not. The documents may come from teaching and research institutions in France or abroad, or from public or private research centers.
L'archive ouverte pluridisciplinaire HAL, est destinée au dépôt et à la diffusion de documents scientifiques de niveau recherche, publiés ou non, émanant des établissements d'enseignement et de recherche français ou étrangers, des laboratoires publics ou privés. 
JOURNAL DE PHYSIQUE

Colloque $\mathrm{Cl}$, supplément au $\mathrm{n}^{\circ} 3$, Tome 48, mars 1987

\title{
DISLOCATION MECHANISMS OF PLASTIC DEFORMATION OF ICE
}

\author{
A. FUKUDA, T. HONDOH* and A. HIGASHI* * \\ Department of Applied Material Science, Muroran Institute of \\ Technology. Muroran, HokkaIdo 050, Japan \\ "Department of Applied Physics, Hokkaido University, \\ Sapporo 060, Japan \\ * Division of Natural Sciences, International Christian \\ University, Mitaka, Tokyo 181, Japan
}

Résumé - La nature et les propriétés des dislocations dans la glace sont parfaitement décrites à l'aide d'observations par topographie de rayons $X$ antérieures et d'une étude récente du comportement dynamique. La valeur très faible de l'énergie de faute dans le plan basal trouvée par notre méthode nous amène à conclure que toutes les dislocations dans la glace pourraient être dissociées jusqu'à plusieurs dizaines ou une centaine de nanomètres, suivant leurs vecteurs de Burgers, sur le plan de base. Le mouvement des dislocations, cependant, est limité au plan basal. La forte anisotropie de la déformation plastique du monocristal de glace est due à cette restriction; le glissement primaire dû au mouvement des dislocations $(1 / 3)\langle 1120\rangle$ sur le plan $(0001)$ est un système de glissement facile dans la glace car les plans de glissement des autres dislocations ne coincident pas avec leur plan dissocié ou le plan basal. Il a été aussi montré que le système de glissement secondaire $\langle 1 \overline{1} 0\rangle /\{10 \overline{1} 0\}$ est dû au glissement sur les plans prismatiques 1010 de dislocations recombinées $(1 / 3)\langle 1120\rangle$. Puisque seuls les très courts segments peuvent glisser sur $\{10 \overline{10}\}$ à cause de la tendance des dislocations à rester sur (000\%), ce système de glissement est moins facile que le glissement primaire en dépit de la plus grande vitesse des segments par rapport au glissement basal. En plus des deux précédents systèmes de glissement qui ne sont pas responsables de la déformation en traction ou en compression le long de l'axe $c$, un mécanisme de montée des dislocations $[0001]$ ou $(1 / 3)<11 \overline{2} 3>$ sur le plan de base est proposé comme troisième système de déformation dans la glace. Par ce mécanisme, le cristal de glace se déforme sous contrainte uniaxiale parallèle à l'axe c avec une vitesse faible limitée par la diffusion mais plus rapide que par un mécanisme diffusionnel de Nabarro-Herring.

\footnotetext{
Abstract

Characters and properties of dislocations in ice are thoroughly reviewed on the basis of the knowledge hitherto obtained by the X-ray topographic method as well as recently found dynamical behavior. Extremely low energy of the faults on the basal plane found by the method leads us to conclude that all of the dislocations in ice should be extended as wide as several tens to one hundred nano-meter, depending upon their Burgers vectors, on the basal plane. The motion of dislocations, therefore, is severely restricted on the basal plane. The strong anisotropy of plastic deformation of ice single crystal is interpreted in terms of this restriction; i.e., the primary slip caused by glide motion of the $(1 / 3)\langle 112 \overline{2}\rangle$ dislocations on (0001) is a unique easy slip system in ice because glide planes of the other dislocations do not coincide with their extended plane or the basal plane. It is also shown that the secondary slip system $\langle 11 \overline{2} 0\rangle /\{10 \overline{1} 0\}$ is due to glide motion of the constricted $(1 / 3)\langle 11 \overline{2} 0\rangle$ dislocations on the prismatic planes $\{10 \overline{1} 0\}$. Since only very short segments can glide on $\{10 \overline{10}\}$ owing to the tendency of the dislocations to lie on (0001), this slip system is far less easier than the primary one in spite of larger velocities of the segments than the basal
} 
glide. In addition to the above two slip systems, which are not responsible for the tensile or compressive deformation along the c-axis, climb mechanism of $[0001]$ or $(1 / 3)<1123\rangle$ dislocations on the basal plane is proposed as the third deformation system in ice. By this mechanism, the ice crystal deforms under uniaxial loading parallel to c-axis at a low rate limited by diffusion process but much faster than by Nabarro-Herring diffusional mechanism.

\section{Introduction}

Dynamical behavior of dislocations in single crystals of ice has been extensively investigated since early 1970s', owing to our developments of the method of growing nearly perfect single crystals of ice and also to the use of a powerful X-ray source for taking X-ray topographs. Major subjects of the study are the dislocation velocity as a function of stress and temperature, the formation of faulted and unfaulted dislocation loops on the process of crystal growth and in rapidly cooled crystal specimens, and the expansion and shrinkage of those loops when specimens are subjected to the heat treatment or to the stress.

Although many papers [1]-[15] have been published on those subjects of research, it is an aim of this paper to summarize about structures and characters of dislocations in ice together with those of stacking faults hitherto clarified by our work and to correlate them to the characters of plastic deformation of ice single crystals. New findings on the dynamical behavior of dislocations in addition to the previous knowledge compose full data for the construction of deformation systems in ice single crystals.

One of the characters of plastic deformation of ice crystal to be interpreted by dislocation mechanism is a remarkable anisotropy in the plastic deformation. The anisotropy was clearly shown in our early work on the stress-strain relation of basal and non-basal slip [16]. The maximum tensile stress is approximately ten times higher for the non-basal slip than for the basal slip. Recent illustration by Duval et al. [17] of the strain rate vs. stress relationship for collected data both on mono- and polycrystals of ice indicates that the flow stress is at least 60 times greater than that on the basal plane, or that the creep rate by basal slip is roughly $10^{4}$ times faster, at a given stress, than that by non-basal slip.

In this paper, details of experiments carried out for making clear the dynamical behavior of dislocations are omitted. Important results will be presented in the following sections. For a convenience of readers, the principal Burgers vectors of ice to be used in the following descriptions are illustrated in Fig. 1. Letter symbols $\mathbf{a}, \mathbf{c}$ and $\mathbf{p}$ will be used occasionally for the vectors $(1 / 3)\langle 11 \overline{2} 0\rangle,[0001]$ and $(1 / 3)\langle 01 \overline{1} 0\rangle$.

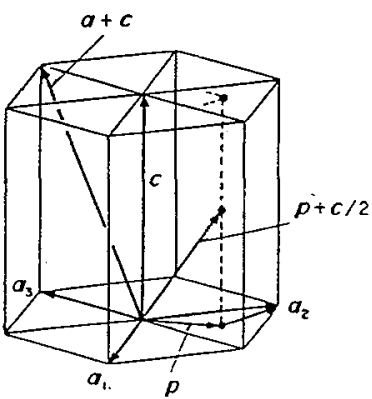

Fig.1 Burgers vectors in ice crystal.
Table I Dislocations in ice

\begin{tabular}{|c|c|c|c|c|}
\hline Type of dislocation & \multicolumn{3}{|c|}{ Burgers vector } & $\begin{array}{l}\text { Energy } \\
\text { (relative value) }\end{array}$ \\
\hline \multirow{3}{*}{ perfect } & $\frac{1}{3}\langle 11 \overline{2} 0\rangle$ & a & 4.52 & 1 \\
\hline & $\langle 0001\rangle$ & c & 7.36 & 2.7 \\
\hline & $\frac{1}{3}\langle 11 \overline{2} 3\rangle$ & $a+c$ & 8.63 & 3.6 \\
\hline \multirow{3}{*}{ partial } & $\frac{1}{3}\langle 10 \overline{1} 0\rangle$ & $\mathbf{P}$ & 2.61 & 0.33 \\
\hline & $\frac{1}{6}\langle 20 \overline{2} 3\rangle$ & $\frac{c}{2}+p$ & 4.51 & 1 \\
\hline & $\frac{1}{2}<0001>$ & $\frac{c}{2}$ & 3.68 & 0.66 \\
\hline
\end{tabular}


2. Characters of dislocations and stacking faults in ice

On the basis of various X-ray topographic observations, dislocations in ice ere now classified as tabulated in Table I. Total energy $E$ of the dislocation is expressed by

$$
E=\frac{K b^{2}}{4 \pi} \ln \left(\frac{r}{r_{0}}\right)
$$

where $K$ is a constant involving the rigidity and the Poisson's ratio of materials and being determined in different manners owing to the crystal structure and the type of dislocation, $b$ the Burgers vector length, $r_{0}$ the core cutoff radius and $r$ the average distance between dislocations. Since the energy E critically depends on $b^{2}$, relative values of $b^{2}$ are tabulated in the column $E$ of the table. The table shows that the perfect dislocation can be dissociated to the partial dislocations in such a manner that

$$
\frac{1}{3}[11 \overline{2} 0] \rightarrow \frac{1}{3}[10 \overline{1} 0]+\frac{1}{3}[01 \overline{1} 0]
$$

or

$$
\mathbf{a} \rightarrow \mathbf{p}_{1}+\mathbf{p}_{2}
$$

because of the energy consideration of

$$
\mathrm{E}_{\mathrm{a}}>\mathrm{E}_{\mathrm{p}_{1}}+\mathrm{E}_{\mathrm{p}_{2}}
$$

The separation between $P_{1}$ and $P_{2}$ partials is dependent on the energy of the stacking fault between them.

The stacking faults have been extensively investigated also by X-ray topography both in fresh single crystals of ice grown from the melt as well as in cooled specimens from aged crystals [9], [12]. In either case, most of the faults were found to be surrounded by dislocations with the Burgers vector $\mathbf{b}=(1 / 6)\langle 20 \overline{2} 3\rangle$ and occasionally found were those surrounded by $\mathbf{b}=(1 / 3)\langle 10 \overline{1} 0\rangle$, both on the basal plane. Stacking faults on the prism plane $\{10 \overline{10}\}$ were found rather rarely on the topographs, but their fault vector has not been determined yet (possibly $(1 / 6)\langle 2023\rangle)$. The stacking fault energy $\gamma_{f}$ for those of $(1 / 6)\langle 20 \overline{2} 3\rangle$ fault vector was determined by the measurements of shrinkage rate of both faulted and unfaulted dislocation loops from X-ray topographs taken intermittenly. It was evaluated to be $0.31 \mathrm{~mJ} / \mathrm{m}^{2}\left(\mathrm{erg} / \mathrm{cm}^{2}\right)$ at $-20{ }^{\circ} \mathrm{C}[12]$. Since the stacking fault with the fault vector of $(1 / 6)\langle 20 \overline{2} 3\rangle$ is accompanied by one layer of cubic structure whereas that of $(1 / 3)\langle 10 \overline{1} 0\rangle$ is accompanied by two cubic layers as shown in Fig. 2 , the stacking fault energy $\gamma_{f}$ for the latter is roughly twice that of the former, that is to say $0.6 \mathrm{~mJ} / \mathrm{m}^{2}$. The other possibie fault on the basal plane is that with the fault vector of $c / 2$ accompanied by three cubic layers as illustrated in Fig. 2(c); i:e., the fault energy can be estimated as $0.9 \mathrm{~mJ} / \mathrm{m}^{2}$. The above-stated results are tabulated in Table II. Since tetrahedral hydrogen bonding such as shown in Fig. 2 cannot be formed for any faults on the prismatic planes, their fault energies should be much higher than those on basal planes.

The width of extended dislocations could be estimated, equating the repulsive force between partials and the attractive force due to the stacking fault energy [14]. Hyperbolas in Fig. 3 show the relationship between the repulsive force and the width between parallel Shockley partials p1 and p2 dissociated from both screw and edge type dislocations of which Burgers vector is $(1 / 3)\langle 11 \overline{2} 0\rangle$. Repulsive force $f$ is expressed by the force per unit length of the dislocation in the unit of $\mathrm{N} / \mathrm{m}$. The equilibrium separation between $\mathbf{p}_{1}$ and $\mathbf{p}_{2}$ partials can be obtained from intersections of those hyperbolas with a horizontal line at a level of attractive force due to the stacking fault energy of $0.6 \mathrm{~mJ} / \mathrm{m}^{2}$. The separation is $20 \mathrm{~nm}$ (200 A) for screw dislocations and $46 \mathrm{~nm}(460 \AA)$ for edge dislocations. Although those separations are too narrow to be distinguished by the X-ray topography, it is now inferable that the most common dislocations in ice on the basal plane 
Table II Stacking faults in ice

\begin{tabular}{lllll} 
plane & Fault vector & $\begin{array}{c}\text { stacking faujt energy } \\
(\mathrm{mJ} / \mathrm{m})\end{array}$ \\
\hline \multirow{3}{*}{$(0001)$} & $\frac{1}{3}\langle 10 \overline{1} 0\rangle$ & $\mathbf{p}$ & 0.6 & (estimated) \\
& $\frac{1}{2}[0001]$ & $\frac{c}{2}$ & 0.9 & (estimated) \\
& $\frac{1}{6}\langle 20 \overline{3} 3\rangle$ & $\frac{c}{2}+p$ & 0.31 (measured)
\end{tabular}

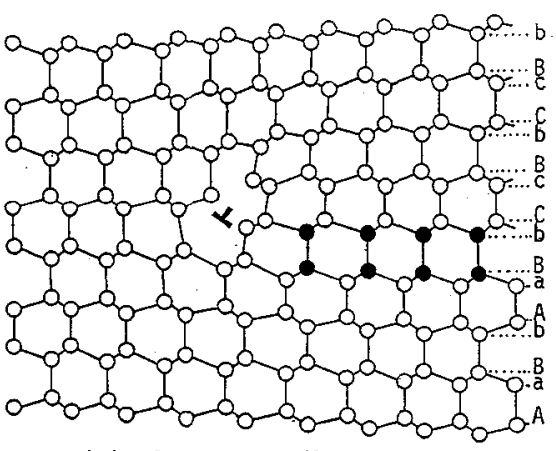

(a) $b=p+c / 2$

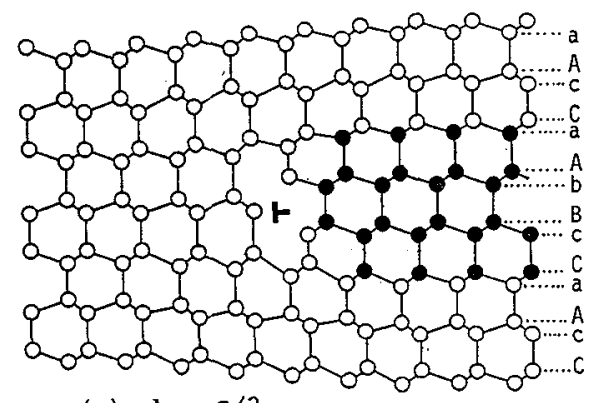

(c) $\quad b=c / 2$

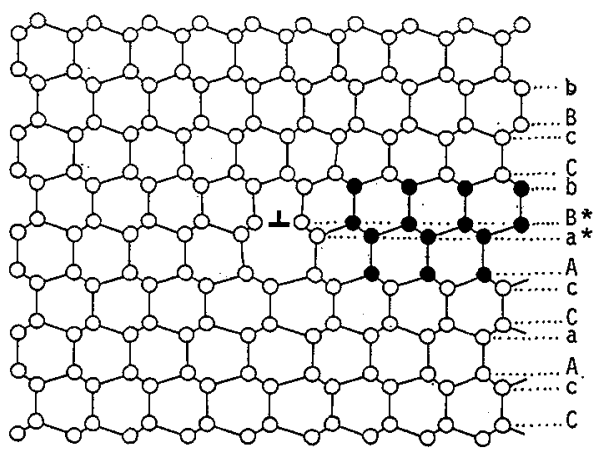

(b) $\mathrm{b}=\mathrm{p}$

Fig. 2 Partial dislocations in ice. The fault vectors of the stacking faults are equal to $b$. Note that the oxygen atoms illustrated by filled circles have the second nearest neiboughs in the cubic structure.

$(b=(1 / 3)\langle 11 \overline{2} 0\rangle)$ which plays dominant role for the basal glide are extended on the basal plane.

Following dissociations are also possible in ice from the energy consideration (see Table I), for the c dislocation

$$
c+\left(\frac{\mathbf{c}}{2}+\mathbf{p}_{1}\right)+\left(\frac{\mathbf{c}}{2}-\mathbf{p}_{1}\right)
$$

or

$$
c \rightarrow \frac{c}{2}+\frac{c}{2}
$$

and for the cta dislocation

$$
c+a \rightarrow\left(\frac{c}{2}+p_{1}\right)+\left(\frac{c}{2}+p_{2}\right)
$$


The widths of these extended dislocations are estimated by the same sort of calculation: (4) $160 \mathrm{~nm}$ for pure screw of $p_{1}$ and $200 \mathrm{~nm}$ for pure edge of $\mathbf{p}_{1}$, (4') $100 \mathrm{~nm}$ and (5) $350 \mathrm{~nm}$ for pure screw of a and $400 \mathrm{~nm}$ for pure edge of a. It should be emphasized that such these surprisingly large width of the extended dislocations in ice are due to extremely low energy of the stacking faults on basal planes.

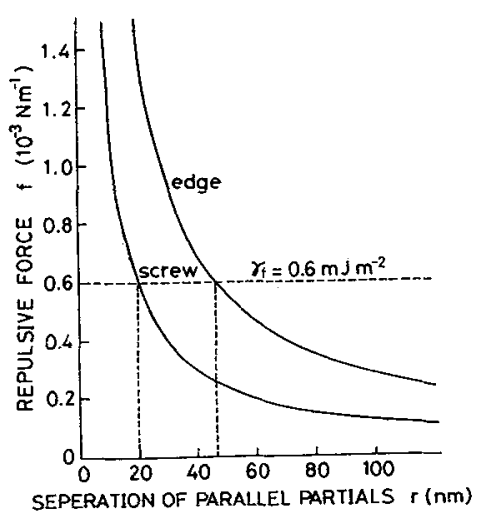

Fig. 3 Repulsive force vs. separation between parallel partials $\mathbf{p}$ in ice.

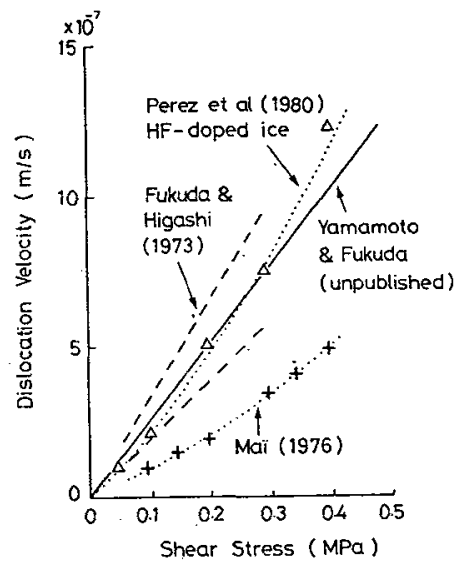

Fig.4 Dislocation velocity vs. shear stress on the basal plane.

\section{Motion of dislocations in ice}

\subsection{The glide motion}

It is well known now that the dominant basal slip in plastic deformation of ice is caused by the glide motion of $(1 / 3)\langle 11 \overline{2} 0\rangle$ dislocations on the basal plane. Since the dislocation is extended on the basal plane as was described in the preceding section, the partial dislocation glides between $a^{*}$-layer and $B^{*}$-layer shown in Fig. 2(b), or a plane of glide set. The molecules on B*-layer, for instance, successively move toward right relative to those on $a^{*}$-layer when the dislocation glides to the right in this figure. The rate controlling process is considered to be the proton rearrangement [18]. Flexible dislocation model proposed by Whitworth [19] based on this idea gave the upper limit of dislocation velocity $v_{d}$ as $v_{d} / b$ being $3001 / \mathrm{s}$ when it is assumed that a flexible partial dislocation is on planes of glide set. This value is still approximately one order of magnitude smaller than that derived from our experimental results as shown in Fig. 4. Our recent results of dislocation velocity [Fukuda et al. to be published] determined by the double exposure method of X-ray topography coincided very well to the mean values for curved and straight individual dislocations as indicated in this figure. Another character to be pointed out on this figure is that the velocity is proportional to the resolved shear stress on the basal plane. Least mean square fitting for all the velocity data obtained at a temperature $\mathrm{T}$ between -1.6 and $-69^{\circ} \mathrm{C}$ and under a shear stress $\tau$ ranging 0.02 and $0.6 \mathrm{MPa}$ gives the following equation for the dislocation velocity $v_{d}$,

$$
V_{d}=c \tau \exp (-U / k T)
$$

where $c=6.4 \mathrm{~m} / \mathrm{Pa} \cdot \mathrm{s}$ and $U=9.9 \times 10^{-20} \mathrm{~J}(\simeq 0.62 \mathrm{eV})$.

Non-linearlity found by Mai and other people [20],[21] might have been caused by some specific obstacles included in a limited number of specimens, rather than the proton disorder. Discrepancy between the measured and theoretical values of dislocation velocity stated above could be settled by improvements of the model. 
Among various possibilities of non-basal glides, only a prism glide of the $(1 / 3)\langle 1120\rangle$ dislocation on a prism plane $\{10 \overline{1} 0\}$ has been observed in $\mathrm{X}$-ray topographs. Since the pure screw $(1 / 3)\langle 11 \overline{2} 0\rangle$ dislocation is extended on the basal plane, it can not move on the prism plane. However, if the edge component lying on the prism plane of the $(1 / 3)\langle 1120\rangle$ dislocation is constricted, this segment is mobile under the non-basal shear stress.

Three topographs in Fig. 5 show a process of the movement of an edge segment on the prism plane under an uniaxial compression of a specimen in which the basal plane was inclined $45^{\circ}$ to the compressive axis. As can be seen in Fig. 5(b), shear stress on a prism plane drove an edge segment to the left dragging screw dipoles on the basal plane. After released the stress, the driven edge segment returned to show a gentle hook. The topograph (b) shows that the edge segment move much faster (probably 10 times or more) than the dislocation on the basal plane under almost the same shear stress. The fact that the basal slip is dominant in spite of faster movement of non-basal glide of dislocations can be attributed to the enormous difference in the dislocation density; edge components on the non-basal plane are only in a short segment with rare occurrence.

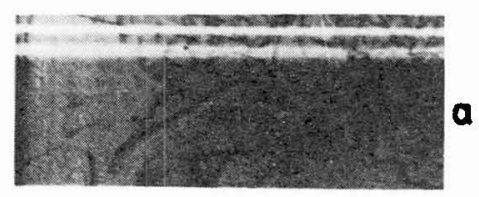

$\sim \mathrm{g}$
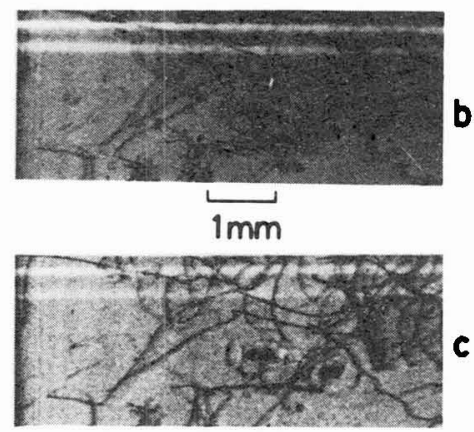

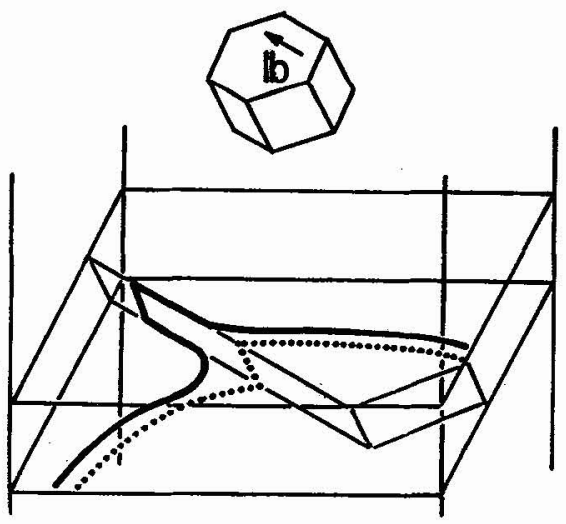

Fig. 5 X-ray topographs showing fast movement of dislocationlying on a prismatic plane.

Although the short edge segments do not contribute quantitatively to the plastic deformation of ice, they play important roles to generate screw dislocations on the basal plane. When an edge segment 1 between two basal planes glides to the direction parallel to the Burgers vector $\mathbf{b}$ owing to non-basal shear stress, it generates extended screw segments $s_{1}$, and $s_{2}$ on both the basal planes as illustrated in Fig, 6. Since the dominant part of the plastic deformation takes place by the movement of those extended screws as described in the basal glide, such a process of multiplication of dislocation is important.

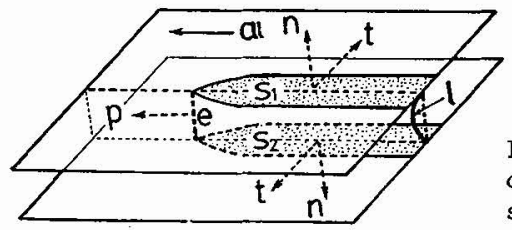

Fig. 6 Formation of screw dislocation dipoles on the basal planes by glide motion of edge segment on the prismatic plane..

Recently, Ahmad et al. [22] found a Frank-Read source operation in an ice crystal with a sequence of X-ray topographs taken by the use of synchrotron radiation source at Daresbury, UK. They interpreted that the F-R source is a step 
from one glide plane to a parallel on a small distance behind. This step seems to be the constricted edge segment of the $(1 / 3)\langle 1120\rangle$ dislocation on the prism plane as illustrated in Fig. 7 (a). As was discussed above, this segment moves fast on the prism plane under stress. In the UK group observation, however, the step was immobile although a resolved stress on the prismatic plane is not presented.

Though our many "in situ" observations of the dynamical behavior of dislocations, it was found that the crystal surface and grain boundaries [13] play important roles of dislocation generation. When a $(1 / 3)\langle 11 \overline{2} 0\rangle$ dislocation hits the surface at oblique intersection of the basal plane as shown in Fig. 7 (a), its end bends to form the non-basal edge segment due to the image force, and then it moves on the prismatic plane under the stress, leaving a screw dipole on the basal plane as illustrated in Fig. 7(b). This effect makes double multiplication of the dislocations on the basal plane at each hit of dislocation to the surface. Other evidences of this multiplication mechanism have been obtained in many $X-r a y$ topographs as shown in Fig. 7(c) to (e). Real formation of the edge segments on the prism plane as illustrated in Fig. 7(a) needs some climb motion in addition to the image force. The fact that the multiplication occurs more frequently after the cooling of a specimen may support this motion.

Other possible non-basal glides are associated with [0001] dislocations on the prism plane $\{10 \overline{1} 0\}$ and $(1 / 3)\langle 11 \overline{2} 3\rangle$ dislocations on the pyramidal plane $\{11 \overline{2} 2\}$. However, those glides have never been observed in our topographic studies in a range below $1.6 \mathrm{MPa}$ of the shear stress. This must be due to the very wide separations between extended partials as described in the preceding section. To constrict the c+a dislocation extended on (0001), a shear stress of about $100 \mathrm{MPa}$ is required while the stress of $13 \mathrm{MPa}$ is sufficient for the a dislocation.

\subsection{The climb motion under stress}

The climb motion of dislocation in ice is also restricted on the basal plane because they are widely extended on it. It was found that dislocation loops lying on the basal plane, often observed in fresh grown single crystals of ice or in cooled specimens, expand or shrink under tensile or compressive stress to direction of c-axis. This implies that the dislocation loop is the interstitial type as was determined previously with grown-in loops by X-ray topographic method. The process of expansion or shrinkage is the climb of edge dislocation caused by absorption or release of interstitials. X-ray topographs of Fig. 8 show the shrinkage process of a dislocation loop under compressive stress. Using the shrinkage rate $F$ observed from such topographs, we can evaluate the rate of plastic deformation due to the compression or tension to the direction of c-axis. In such a deformation where no glide motion of dislocation occurs, mechanisms of plastic deformation involve the diffusion of point defects (Nabarro-Herring diffusion mechanism) between the upper, bottom ends and sides of a specimen, in addition to the climb mechanism stated above. Now, let us compare these two mechanisms quantitatively.

For the climb mechanism, vertical strain rate $\varepsilon_{\text {c }}$ of a specimen subjected to compressive or tensile stress along vertical c-axis is ${ }^{c}$ given by

$$
\dot{\varepsilon}_{c}=2 \pi \rho_{c} b_{c} \dot{r}
$$

in which $\rho_{c}$ is the density of dislocations of which Burgers vector is [0001] or $(1 / 3)\langle 11 \overline{2} 3\rangle$, and $b$ the component of the Burgers vector to the direction of $c-$ axis, i.e. $b_{c}=c$. The climb velocity $\dot{r}$ can be expressed as follows when the loop radius $r$ is sufficiently small compared to the specimen thickness and the loop density is low,

$$
\dot{r}=-\frac{\mathrm{r}}{\mathrm{r}} \frac{2 \mathrm{D} \Omega}{\mathrm{kT}} \sigma
$$

In this equation, $r$ is the effective radius of dislocation loop as a source of point defects and $r$ ff $/ r \simeq 0.64$. D is the self diffusion coefficient of point defects, $\Omega$ the molecufar volume and $\sigma$ the vertical stress. Therefore, the strain 


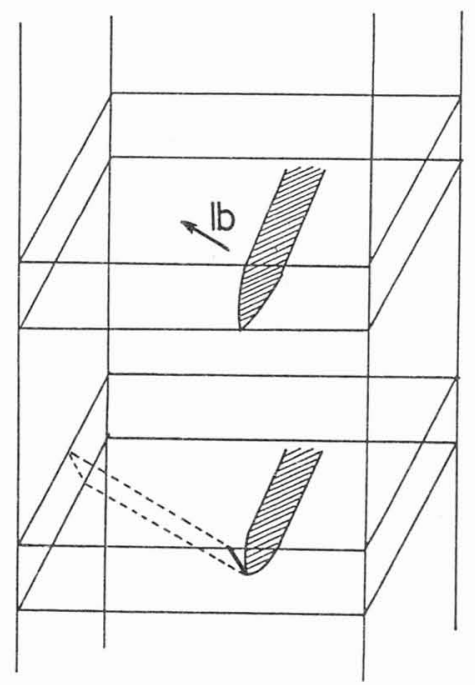

(a)

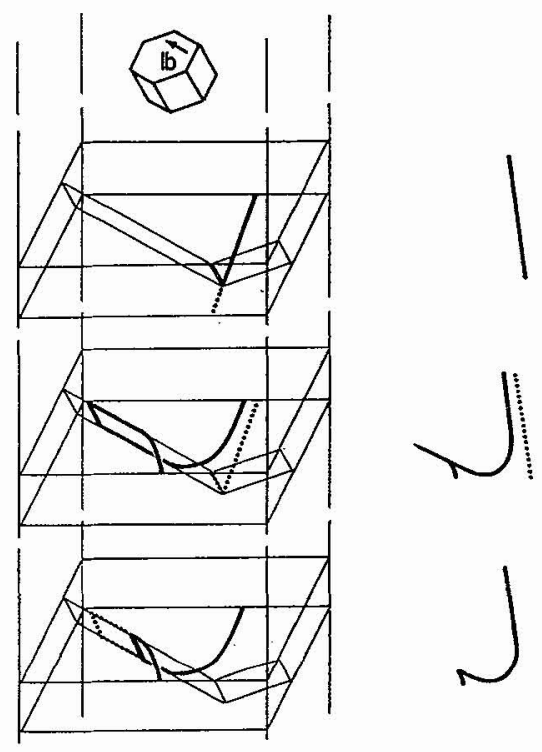

(b)
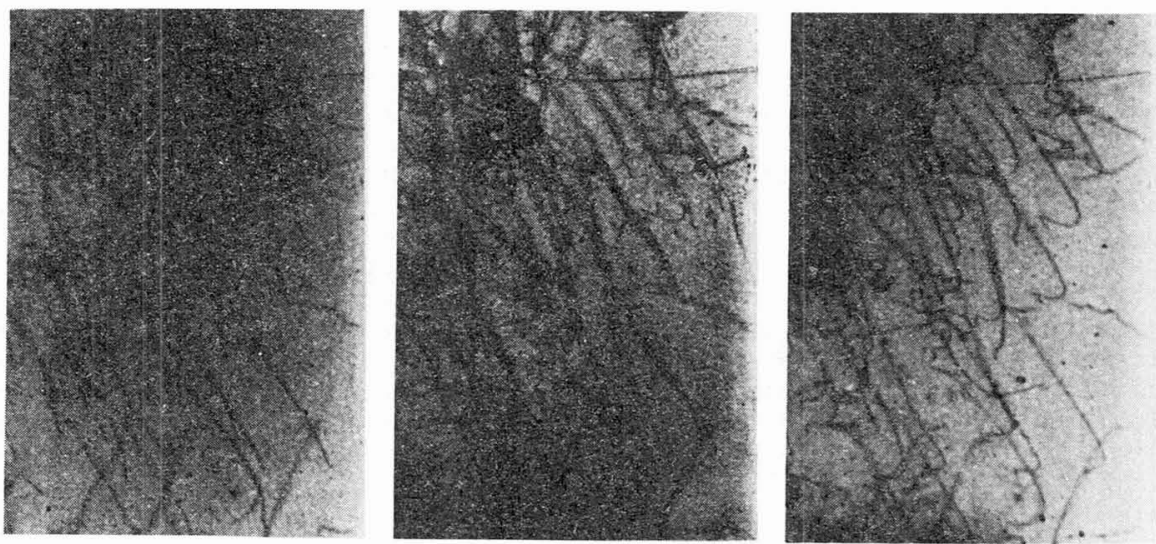

(c) 9

(d)

(e)

Fig. 7 Cross slip of the a dislocation from basal glide to prismatic one. (a) Constricted basal dislocation at the surface.

(b) Schematic illustration of the cross slip to the prismatic plane. (c)-(e) Double exposure X-ray topography. (c)before loading, (e) after loading and (d) double exposure topograph shows fast movement of dislocation close to the surface. The shape of the dislocation is schematically illustrated in the right of (b).

rate at a temperature $\mathrm{T}$ is given by

$$
\dot{\varepsilon}_{c}=\frac{r_{\text {eff }}}{r} \frac{4 \pi D \Omega}{k T} \rho_{c} \sigma
$$


On the other hand, the strain rate by the mechanism of Nabarro-Herring $\dot{\varepsilon}_{\mathrm{NH}}$ is given by

$$
\dot{\varepsilon}_{\mathrm{NH}}=\frac{1}{L_{2}} \frac{2 \mathrm{D} \Omega}{\mathrm{kT}} \sigma
$$

where $L$ is a dimension of a specimen. For the comparison, the ratio of the strain rate by two mechanism can be reduced as

$$
\frac{\varepsilon_{C}}{\varepsilon_{N H}}=\frac{r_{\text {eff }}}{r} 2 \pi \rho_{C} L^{2}
$$

Now, if we put $\rho \simeq 10^{8} \mathrm{~m}^{-2}, \quad \mathrm{~L} \simeq 5 \times 10^{-2} \mathrm{~m}$, then this ratio take a value approximately $10^{6}$. This means that the contribution of the climb mechanism exceeds very much to that of the Nabarro-Herring diffusion mechanism. We may need to revise the deformation mechanism map in this respect. Actually, the measured macroscopic vertical strain rate $\dot{\varepsilon}_{\mathrm{c}}$ was almost $10^{6}$ times of the estimated $\dot{\varepsilon}_{\mathrm{NH}}$ from the specimen size, applied stress and appropriate values for $D$ and $\Omega$ in this experiment.

The climb motion on the non-basal planes is possible when the dislocation is constricted at a surface as shown in Fig. 7 or under high stress overcoming the repulsive force between two partials. Formation of small angle grain boundaries must involve such climb motion under very high stress due to interactions among densely distributed dislocations.

\section{Deformation systems in single crystals of ice}

We have now reached to such a stage that various slip systems in ice can be compared semiquantitatively based on compiled data on the dynamical characters of dislocations as described in the preceding section. The most common dislocations in ice are those of Burgers vector $(1 / 3)\langle 11 \overline{2} 0\rangle$ which play a dominant role for the basal slip with which the strain rate is much faster than non-basal slip. When strains are in a Cartesian coordinate set $X_{1}, X_{2}, X_{3}$ with $X_{1}$ and $X_{2}$ in the basal plane and $X_{3}$ normal to $i t$, the glide motion of $\left.(1 / 3)<11 \overline{2} 0\right\rangle$ on the prism plane $\{10 \overline{1}$ $0\}$ is observed but it contributes very little to the macroscopic strain $\varepsilon_{11}\left(\varepsilon_{22}\right)$ or $\varepsilon_{12}$.

Anisotropy of the plastic deformation of ice, very large difference in the strain rate between the basal silp and non-basal slip can be attributed to the large difference of the dislocation density between those on the basal plane and those on the non-basal plane. The (1/3)[1120] dislocation is found to be extended to the partials of $(1 / 3)[10 \overline{1} 0]$ and $(1 / 3)[01 \overline{1} 0]$ on the basal plane and this extended state makes it stable configuration in the crystal. It is difficult to make it constricted because of the large repulsive force between partials as described in the preceding section. Therefore, only short segments of constricted edge component of $(1 / 3)\langle 1120\rangle$ dislocation can move on the prismatic plane as shown in Fig. 4, but they do not contribute much to the plastic deformation because of much less density than those on the basal plane. To deform the crystal at a higher rate only by this secondary slip system, sufficiently large stress for constricting the extended dislocations has to be applied.

It was found that the climb of dislocation loops of the [0001] or $(1 / 3)\langle 11 \overline{2} 3\rangle$ Burgers vectors on the basal plane plays an important role for the longitudinal deformation of a rod specimen of ice single crystal elongated to the direction of c-axis, that is to say giving the strain $\varepsilon_{33}$, compared to the Nabarro-Herring diffusional mechanism of deformation. All these deformation systems in configuration to the dislocation motions are tabulated in Table III.

In the last, it may be pertinent to point out the importance of the nonuniform distribution of $(1 / 3)\langle 112 \overline{2} 0\rangle$ dislocations on the basal plane or the formation of small angle grain boundaries of single crystals and for deformation of polycrystalline ice. The fact that slip lines were observed only in the direction parallel to the basal plane in shadow topographs of bent single crystals 
of ice (Nakaya, 1954 [23]) suggests this importance. Other strain components, in addition to $\varepsilon_{13}$ and $\varepsilon_{23}$ can be produced only by basal glide when the $(1 / 3)\langle 11 \overline{2} 0\rangle$ dislocations generated distribute non-uniformly to bend the crystal. If the deformation is carried out at an elevated temperature, small angle grain boundaries must be formed by redistribution of such dislocations to reduce strain energy. In fact, many small angle grain boundaries are frequently observed in polycrystalline ice deformed above $-20^{\circ} \mathrm{C}$.

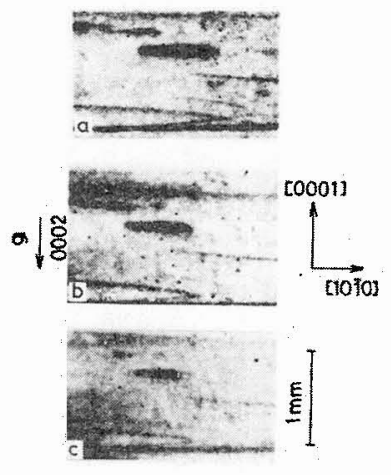

\begin{tabular}{lcccc} 
& Table III & deformation systems in ice \\
\hline $\begin{array}{l}\text { Type of } \\
\text { dislocation motion }\end{array}$ & plane & b & strain & strain rate \\
\hline $\begin{array}{l}\text { Glide on basal plane } \\
\text { (primary slip system) }\end{array}$ & $(0001)$ & $\frac{1}{3}\langle 11 \overline{2} 0\rangle$ & $\varepsilon_{13}, \varepsilon_{23}$ & very large \\
$\begin{array}{l}\text { Glide on prismatic plane } \\
\text { (secondary slip system) }\end{array}$ & $\{10 \overline{0} 0\}$ & $\frac{1}{3}\langle 11 \overline{2} 0\rangle \varepsilon_{11}\left(\varepsilon_{22}\right), \varepsilon_{12}$ & small \\
\hline Climb on basal plane & $(0001)$ & {$[0001]$} & & \\
\hline
\end{tabular}

Fig. 8 Climb motion of dislocations under stress.

Acknowlecigements

The authors wish to express their sincere gratitude to $\mathrm{Mr}$. Y. Yamamoto and Mr. S. Amakai for their efforts of carrying out experiments of measuring dislocation velocity and of shrinkage of stacking faults under stress.

\section{References}

[1] Fukuda,A. and Higashi,A., Proc. int. Conf. on Physics of Ice, Munich (1968), Riehl,N., Bullemer,B and Engelhardt,H., eds, Physics of Ice, Plenum Press (1969) 239.

[2] Fukuda,A. and Higashi,A., Jpn. J. Appl. Phys. 8 (1969) 993.

[3] Oguro,M. and Higashi,A., Phil. Mag. 24 (1971) 713 .

[4] Fukuda,A. and Higashi,A., Crystal Lattice Defects. 4 (1973) 203.

[5] Oguro, M. and Higashi, A., Proc. Int. Symp. on Physics and Chemistry of Ice, Ottawa (1972), Whalley,E., Jones,S.T. and Gold,L.W., eds, Physics and Chemistry of Ice, The Royal Society of Canada (1973) 338.

[6] Higashi,A., J. Cryst. Growth. 24/25 (1974) 102.

[7] Oguro,M. and Higashi,A., Jpn. J. Appl. Phys. 18 (1979) 1897.

[8] Oguro,M. and Higashi,A., J. Cryst. Growth 51 (1981) 71.

[9] Hondoh,T., Itoh, T and Higashi, A., Jpn. J. App1. Phys. 20 (1981) L737.

[10] Goto,K., Hondoh, T. and Higashi, A., Proc. Int. Conf on Point Defects and Defects and Defect Interaction in Metals, Kyoto (1981), Takamura,J., Doyama, M. and Kiritani,M., eds, Point Defects and Defect Interaction in Metals, Univ. Tokyo Press (1982) 174.

[11] Hondoh,T., Itoh,T. and Higashi,A., Proc. Int. Conf on Point Defects and Defects and Defect Interaction in Metals, Kyoto (1981), Takamura,J., Doyama, M. and Kiritani,M., eds, Point Defects and Defect Interaction in Metals, Univ. Tokyo Press (1982) 599.

[12] Hondoh,T., Itoh,T., Amakai,S., Goto,K. and Higashi,A., J. Phys. Chem. 87 (1983) 4040.

[13] Hondoh,T. and Higashi,A., J. Phys. Chem. 87 (1983) 4044. 
[14] Higashi,A., Fukuda,A., Hondoh,'T., Goto,K. and Amakai,S., Proc. Int. Conf. on Dislocations in Solids, Tokyo (1984), Suzuki,H., Ninomiya,T., Sumino,K. and Takeuchi,S., eds, Dislocations in Solids, Univ. Tokyo Press (1985) 511.

[15] Goto,K., Hondoh,T. and Higashi,A., Jpn. J. Appl. Phys. 25 (1986) 351.

[16] Higashi, A., Mae,S. and Fukuda, A., Proc. Int. Conf. on Strength of Metals and Alloys, Tokyo (1967), Japan Inst. Metals (1968) 784.

[17] Duval,P., Ashby,M.F. and Anderman,I., J. Phys. Chem. 87 (1983) 4066.

[18] Glen,J.W., Phys Kondens Matter. 7 (1968) 43.

[19] Whitworth,R.W., J. Phys. Chem. $\frac{87}{}$ (1983) 4074.

[20] Mai,C., C.R. Acad. Sci. Paris, SerB, 282 (1976) 515.

[21] Perez,J., Mai,C. and Vassoille,R., J. Glaciology, 25 (1980) 133.

[22] Ahmad,S., Ohtomo,M. and Whitworth,R.W., Nature, ${ }^{2} \mathrm{~S} 319^{2} \overline{\mathrm{SG}}$ (1986) 659.

[23] Nakaya, U., SIPRE res. rep. 28 (1958) 1.

\section{COMMENTS}

V.F. PETRENKO

What temperatures were use in different experiments of dislocation velocity measurements shown at your united diagramm?

Answer :

The diagram which was shown (fig. 4 in the paper) is the assemblage of data reduced to at $-22^{\circ} \mathrm{C}$. Of course, $V d\left(\tau, T^{\prime}\right)$ were obtained from many experiments in temperature range of $-10^{\circ} \mathrm{C} \sim-25^{\circ} \mathrm{C}$. Discrepancies of our data from MaI (Lyon) might be caused by the too slow velocity observed in MaI's ice sample which might have specific obstacles for the dislocation motion.

Remark of V.F. PETRENKO :

Then, I think we are not now in the position for an objective comparison of experimental data.

Answer :

Since our recent results (Fukuda, Yamamoto) were obtained from many data (averaged by least square), we are confident with our results. 